\title{
Cavernous Sinus Thrombosis in ENT Practice
}

\author{
Michael AB Naafs* \\ Naafs International Health Consultancy, Europe
}

Submission: September 16, 2017; Published: September 25, 2017

*Corresponding author: Michael AB Naafs, Internist-endocrinologist with a long clinical career in internal medicine and endocrinology, Naafs International Health Consultancy, Dutch, Europe, Email: naafsmichael@gmail.com

Abstract

This mini-review discusses the changing clinical picture of cavernous sinus thrombosis in ENT practice from a septic origin to a more multifactorial aseptic origin during the last two decades.Risk factors, changing imaging modalities and developments in anticoagulant treatment,fibrinolysis and catheter applied thrombectomy techniques are reviewed. Those who perform rhinoplasty procedures must beware of cavernous sinus thrombosis as a complication.

\section{Introduction}

Cavernous sinus thrombosis (CST) was first described by Bright in 1831[1]. The two cavernous sinuses are located on both sides of the sella turcica.Important structures are located in, or run through the cavernous sinus,including the pituitary gland,cranial nerves 3,4 and 5 and the internal carotid arteries [2,3]. The cavernous sinuses recieve blood from the superior ophthalmic and cerebral veins,the sphenoparietal sinuses and emissary veins. The cavernous sinuses also communicate with the deep facial and inferior ophthalmic veins.Many of these veins have no valves and blood can flow in either direction.,depending on pressure gradients.This may be a reason infection spreads easily and thrombosis occurs [4,5]. Infectious CST is defined as a septic thrombophlebitis that typically originates from an infection in the face,sinuses, ears,orbits,teeth,but bacterial seeding from a distant site has also been reported as a cause of septic CST [6]. The incidence of CST is low in Western societies.A nationwide hospital survey in Portugal showed an incidence of 0,22/100.000/year and a well-designed cross sectional epidemiological Dutch study showed an incidence of $1,31 / 100.000 /$ year $[7,8]$.

However in countries like India with a high prevalence of infectious diseases as tuberculosis and HIV-Aids the incidence might be considerable higher. CST is seen there frequently in the puerperium and in young stroke patients $[9,10]$. These studies have shifted the paradigm of a septic thrombophlebitis origin to a more multifactorial aseptic cause of CST.In both situations the ENT surgeon will be consulted. In this mini-review the changing origin of CST and the application of interventional therapies as endovascular thrombectomy, thrombolysis are discussed. As CST evolved as a complication in maxillofacial surgery eg rhinoplasty in the last two decades this subject will be addressed also.

\section{Risk factors CST}

Sphenoid and ethmoid sinusitis are still common causes for septic CST. Other risk factors are dental infections,otitis media,tonsilitis and peritonsilar abscess, meningitis, mastoiditis and osteomyelitis of the maxilla [2,3]. Aseptic causes of CST are trauma, postsurgery including rhinoplasty,maxilla surgery, tooth extractions and cataract extractions. Hematologic risk factors are acute lymphocytic leukemia, lymfoma's, polycythemia vera,hypercoagulable states as in the puerperium, deficiencies of anticoagulants as protein C, S, Factor 5 Leiden, antithrombin 3 and the lupus anticoagulans syndrome.Nasopharyngeal tumors, meningeoma's, pituitay tumors, craniopharyngeoma's or metastases of distant tumors are another cause or risk factor.

\section{Symptoms}

The clinical presentation is usually due to the venous obstruction as well as impairment of the cranial nerves that are near the cavernous sinus. Headache is the most common presenting symptom. The headache is sharp,increases progressively and is usually located to the regions innervated by the ophthalmic and maxillary branch of the trigeminal nerve. A sinusitis or a midface infection as eg a furuncle may be present.Not all patients have periorbital edemain the early stages. Without effective therapy signs appear in the contralateral eye by spreading to the contralateral cavernous sinus through the communicating veins. Eye swelling begins as a unilateral process and spreads to the other eye within 
24-48 hours via the intercavernous sinuses.This is pathognomic for CST.

Chemosis results from occlusion of the opthalmic veins. Lateral gaze palsy by nervus 6 involvement is usually seen first due to compression. Later ptosis, mydriasus and eye muscle weakness fom cranial nerve 3 dysfunction can occur. Thereafter manifestations of increased retrobulbar pressure may follow as exopthalmus, double vision and opthalmoplegia. Signs of increased intraocular pressure are sluggish pupillary responses and worsening visual acquity due to traction on the optic nerve and central retinal artery. Meningeal signs, including nuchal rigidity and Kernig and Brudzinski signs may be noted. Systemic signs of sepsis are late findings. They include chills, fever, seizures, delirium, shock and coma.

\section{Microbiology of septic CST}

The most commonly identified pathogen in patients with septic CST continues to be Staphylococcus Aureus isolated in $60 \%$ to $70 \%$ of patients. Less frequently identified are Streptococcus pneumoniae, gram-negative bacilli and anaerobes [11,12]. Blood cultures are commonly positive in approximately $70 \%$ of cases in patients with acute fulminant disease. Cerebrospinal fluid, abnormal in terms of elevated white blood cell counts and protein levels, is culture positive in only $20 \%$ of cases $[13,14]$. Coccididomycosis, cytomegalovirus and herpes simplex virus and Aspergillus fumigatus have been implicated too [15-18]. Tuberculous meningitis is the most frequent cause in India and Pakistan followed by pyogenic meningitis [14]. An increased risk in HIV-Aids has been reported but it appears HIV infection doesn't play directly a significant role itself. It seems that oppurtunic infections or coagulopathy in HIV infection are required to develop these complications [19].

\section{Differential diagnosis CST}

These include cellulitis, orbital infections, periorbital infections, epidural hematoma, epidural abscess, subdural hematoma and acute angle closure glaucoma.

\section{Diagnosis CST}

CST is a clinical diagnosis however MRI with contrast is the modality of choice to confirm its presence and to differentiate it from alternatives as orbital cellulitis which may have a similar clinical presentation. CT scan without contrast shows a high density thrombus in the cavernous sinus in only $25 \%$. Contrast CT shows a distended cavernous sinus with a non-fat density filling defect [20]. MRI (T1 and T2) shows an absent flow void.Signals vary depending on the age of the thrombus but will be abnormal. Contrast enhancement or lack of is not a reliable indicator as the organizing thrombus can enhance. The diagnosis can generally made by venography [21]. Digital subtraction carotid angiography is seldom necessary as MRI can also detect narrowing of the cavernous sinus part of the internal caroti artery. In the very small paeditrician patients ultrasound can be used.

\section{Treatment}

Septic CST should be treated aggressively by antibiotic administration. Although S.aureus is the usual cause broad spectrum antibiotics should be instituded promptly pending the outcome ofcultures.Empiric antibiotic therapy shoukd include a penicillinase-resistant penicillin plus a third or fourth generation cephalosporin. If a dental or other anaerobic infection is suspected an anaerobic coverage should also be added. I.V antibiotics are recommended for 3-4 weeks.Anticoagulants as heparin should be considered to prevent further thrombosis and to reduce the incidence of septic emboli [22].

\section{Aseptic CST}

Aseptic CST is still a rare disorder accounting for approximately $1 \%$ of strokes. CST is more common in patients with a history of thrombophilia,woman on oral contraceptives or during pregnancy [23-27]. The diagnosis is often delayed approximately 4-7 days after symptoms onset [28]. The majority of patients present under the age of 50 years $(80 \%)$ with a mean age of 39 years $[23,24,28]$. Less than $10 \%$ is older than 60 years [25,28]. CST is most often multifactorial such as infection in the patient with thrombophilia [29]. Multiple risk factors are found in 50\% of cases [30]. Laboratory examination including complete blood cell count, metabolic panel and coagulation shoul be obtained. D-dimer is elevated in these patients $[26,27,31]$. One study found a false negative rate of $24 \%$ and it is normal in $40 \%$ of patients with isolated headache and no other symptoms [31]. Thus this test must not be relied on to rule out the condition $[32,33]$.

Patients with signs concerning for increased intracranial pressure (ICP), posturing,change in breathing, decreased mental status require action immediately. Elevation of the head of the bed,mannitol or hypertonic saline infusion, admission to an intensive care unit and ICP monitoring are required [25-27,34]. If these are ineffective at initial ICP management decompressive hemicraniectomy may be needed [34,35]. Anticoagulation has been controversial in the past as rates of intracranial hemorrhage (ICH) approach to $50 \%$ before treatment $[22,24,36]$. However the presence of ICH is not a contraindication for anticogulation. Literature has demonstrated that no new diagnosis of symptomatic ICH has occured with anticoagulation therapy despite the presence of ICH on initial imaging $[22,24,26,36]$. Thus anticoagulation is warranted with or without the presence of intracranial hemorrhage,as anticoagulation is associated with a significant reduction in death [23-28,36].

Supportive care includes addressing risk factors such as oral contraceptives,treating infection if present, seizure prophylaxis if the patient experiences a seizure with an associated supratentorial lesion such as edema, hemorrhage or infarction on imaging. Further testing includes testing for thrombophilia. Duration of anticoagulation is 3-6 months if provoked and 6-12 months if unprovoked. Follow-up imaging including CT or MRI at 3-6 


\section{Global Journal of Otolaryngology}

months is required to assess for recanalization of the affected area [24-28]. The mortality is 4,3\%-5,6\% during the acute event and hospitalization. This is due to herniation [24-28]. The majority, $88 \%$, experience complete recovery or are left with only mild deficits. Trials to the use of direct anticoagulants (DOCAs) are not available yet Systemic thrombolysis and catheter delivered local thrombolysis should probably be reserved for those patients who rapidly decline despite adequate anticoagulation given the evidence supporting heparin and low molecukar weight heparin (LMWH) efficacy.

Thrombolytic agents applied with endovascular jugular or femoral access have been used since 1971.Endovascular thrombolysis is reserved for severe cases as mentioned above [37]. In the ISCVT study $2 \%$ of patients received thrombolysis and $1 \%$ of patients received decompressive craniectomy [29,37] In the two largest series where fibrinolytic agents were used blood flow was restored in the majority of cases $(71,4 \%)[38,39]$. Apparently local fibrinolysis restores blood flow more quickly and efficiently than heparin but carries the risk of hemorrhage. Currently there have been no clear indications for the use of local or systemic thrombolytic agents due to the lack of conclusive studies supporting it [40]. Recently the enrollment for the Thrombollysis or Anticoagulation for Cerebral Venous Thrombosis trial (TOACT) has been terminated. Intake started at September 15th, 2010 Results are awaiting soon [41]. During local thrombolysis an effort for thrombectomy by suction can be performed.Open surgical thrombectomy has been performed anecdotically and the literature contains no recommendations for its use. Reported complications occuring after rhinoplasty are necrosis of the eyelids due to infection, rhinoliquorrhea, brain damage, fistulae between the cavernous sinuses and thrombosis of the cavernous sinus $[42,43]$. For that reason ENT surgeons,plastic-aesthetic and maxillofacial surgeons should beware of risk factors as thrombophilia, oral contraceptive use, former deep venous thrombosis or multple lung emboli, puerperium history as well as elementary knowledge of anticoagulation and thrombolysis in case of complicating cavernous sinus thrombosis.

\section{Conclusion}

In the ENT practice the clinical picture of cavernous sinus thrombosis has changed from a septic origin to a more multifactorial aseptic origin during the last two decades. Nowadays risk factors as thrombophilia, oral contraceptive use,presence of haematologic and other malignancies and a history of deep vein thrombosis in the puerperium should be taken in account.Imaging modalities to establish the clinical diagnosis have changed enormously. Treatment requires now elementary knowledge of anticoagulation, fibrinolysis and catheter applied thrombectomy techniques. As thrombophilia and ENT infection can coexist the ENT surgeon will be consulted in both situations. Those who perform rhinoplasty procedures should be aware of cavernous sinus thrombosis as a complication.

\section{References}

1. sSingh Y, Singh M, Saxena SR, Kumar J (2014) Pansinusitis,cavernous sinus thrombosis and cerebral infarction. J Med Invest Pract 9(2): 9597.

2. Elbright JR, Pace MT, Niazi AF (2001) Septic thrombosis of the cavernous sinuses. Arch Int Med 161: 2671-2676.

3. Pavolvich P, Looi A, Rootman J (2006) Septic thrombosis of the cavernous sinus: two different mechanisms. Orbit 25(1): 39-43.

4. Desa V, Green R (2012) Cavernous sinus thrombosis: current therapy. J.Oral Maxillofacial Surg 70(9): 2085-2091.

5. Suntrup S, Kemmling A, Rainer D, Niederstadt T, Ritter MA (2012) Septic cavernous sinus thrombosis complicated by occlusion of the internal carotid artery and multiple embolic strokes after syrgery of an anorectal abscess: a clinical chameleon. Neurologist 18(5): 310-312.

6. Ferro JM, Correla M, Pontes C, Baptista MV, Pita F (2001) Cerebral Venous Thrombosis Portugese Collaborative Study Group (Veneport). Cerebral vein and dural sinus thrombosis in Portugal: 1980-1998. Cerebrovasc Dis 11(3): 177-182.

7. Coutinho JM, Zuurbier SM, Aramideh M, Stam J (2012) The incidence of cerebral venous thrombosis : A cross sectional study. Stroke 43(12): 3375-3377.

8. Nagaraja D, Taly A.B, Das S (1989) Puerperal cerebral venous thrombosis in India. Progr Clin Neurosci, In Shinka KK, Chandra P (Eds.), NSI Publication Ranchi, India, Pp. 165-171.

9. Panagariya A, Maru A (1997) Cerebral venous thrombosis in pregnancy and puerperium: A prospective study. J Assoc Physicians India 45(11): 857-859.

10. Garcia RC, Perez JS, Gias LN (2007) Cavernous sinus metastasis from oropharyngeal squamous cell carcinoma. Med Oral Patol Oral Circ Bucal 12(2): E166-170.

11. Southwick FS, Richardson EP, Swartz MN (1986) Septic thrombosis of the venous dural sinuses. Medicine (Baltimore) 65(2): 82-106.

12. Crassard L, Bousser MG (2004) Cerebral venous thrombosis. J Neuroophthalmol 24: 156-163.

13. Fillipidis A, Kapsalaki E, Patramani G, Fountas KN (2009) Cerebral venous sinus thrombosis: review of the demographics, pathophysiology and treatment. Neurosurg Focus 27(5): E3.

14. Ruggieri M, Pavone L, Musumeci S, Polizzi A (1998) Thalamic syndrome in children with measles infection and selective reversible thalamic involvement. Pediatrics 101k(1 Pt 1): 112-119.

15. Heller C, Heinecke A, Junker R, Knofler R, Kurnik K et al. (2003) Cerebral venous thrombosis in children: a multifactorial origin. Circulation 108(11): 1362-1367.

16. Sekhar LN, Dujovny M, Rao GR (1980) Carotid-cavernous sinus thrombosis caused by Aspergillus fumigatus. J Neurosurg 52(1): 120 125.

17. Meyohas MC, Roullet E, Rouzioux C, Aymard A, Pelosse B et al. (1989) Cerebral venous thrombosis and dual primary infection with human immunodeficiency virus and cytomegalovirus. J Neurol Neurosurg Psychiatry 52(8): 1010-1011.

18. Beishuizen A, Derksen-Lubsen G, Los F, H J Neijens, P H Rothbarth et al. (1989) An infant with Aids. Ned Tijdschr. Geneeskd 133(3): 123-126.

19. Rodallec MH, Krainik A, Feydy A, Marc Zins, JM Columbani et al. (2006) Cerebral venous thrombosis and multidetector CT angiography: tips and tricks. Radiographics 26( Suppl 1): 55-118. 
20. Leach J, Fortuna R, Jones B, Gaskill-Shipley M (2006) Imaging of Cerebral Venous Thrombosis: Current Techniques, Spectrum of Findings and Diagnostic Pitfalls. Radiographics 26(Suppl 1): 519-541.

21. Coutinho J, de Bruijn SF, Deveber G, Stam J (2011) Anticoagulation for cerebral venous sinus thrombosis. Cochrane Database Syst Rev Aug 10(8): CD 002005.

22. Piazza G (2012) Cerebral venous thrombosis. Circulation 125: 1704 1709.

23. Tharell SE, Parry-Jones AR, Punter M (2015) Cerebral venous thrombosis- A primer for the hematologist. Blood Reviews 29: 45-50.

24. Bousser MG, Ferro JM (2007) Cerebral venous thrombosis : an update. Lancet Neurology 6(2): 162-170.

25. Stam J (2005) Thrombosis of the cerebral veins and sinuses. N Engl J Med 352(17): 1791-1798.

26. Coutinho JM, Ferro JM, Canhao P, Cantu C, Stam J, et al. (2009) Cerebral venous and sinus thrombosis in women. Stroke 40(7): 2356-2361.

27. Ferro JM, Canhao P, Stam J, Massaro A, Kasner SE, et al. (2009) Delay in the diagnosis of cerebral vein and dural sinus thrombosis : influence on outcome. Stroke 40(9): 3133-3138.

28. Ferro JM, Canhao P, Stam J, Bousser MG, Barinagarrementeria F et al. (2004) Prognosis of cerebral vein and dural sinus thrombosis: results of the International Study on Cerebral Vein and Dural Sinus Thrombosis (ISCVT). Stroke 35(3): 664-670.

29. Canhao P, Ferro JM, Lindgren AG, Stam J, Bousser MG et al. (2005) Causes and predictors of death in cerebral venous thrombosis. Stroke 36(8): 1720-1753.

30. Tanislav C, Siekmann R, Sieweke N, Kaps M, Slotz E et al. (2011) Cerebral vein thrombosis:clinical manifestations and diagnosis. BMC Neurology p.11-69.

31. Crassard I, Soria C, Tzourio C, Drouet L, Bousser MG, et al. (2005) A negative $\mathrm{D}$-dimer assay does not rule out cerebral venous thrombosis: a series of seventy-three patients. Stroke 36(8): 1716-1719.
32. Kosinski CM, Mull M, Schwarz M, Koch B, Biniek R, et al. (2004) Do normal D-dimer levels reliably exclude cerebral sinus thrombosis? Stroke 35(12): 2820-2825.

33. Bullock R, Clifton G (1995) Guidelines for the management of Severe Brain Injury, Brain Trauma Foundation/ American Association of Neurologic Surgeons. NewYork, USA.

34. Ferro JM, Crassard I, Coutinho JM, Derex L, Lichy C et al. (2011) Decompressive surgery in cerebrovenous thrombosis : a multicenter registry and a systematic review of individual patient data. Stroke 42(10): 2825-2831.

35. Tait C, Baglin T, Watson H, Laffan M, Makris M et al. (2012) Guidelines on the investigation and management of venous thrombosis at unusual sites. Br J Haematol 159(1): 28-38.

36. Coutinho JM, Seelig R, Bousser MG, Canhao P, Ferro JM et al. (2011) Treatment variations in cerebral venous thrombosis: An international survey. Cerebrovascular Diseases 3293): 298-300.

37. Kim SY, Sub JH (1997) Direct endovascular thrombolytic therapy for dural sinus thrombosis: Infusion of alteplase. AJNR Am J Neuroradiol 18(4): 639-645.

38. Horowitz M, Purdy P, Unwin H, Greenlee R, Hise J et al. (1995) Treatment of dutal sinus thrombosis using selective cathetrization and urokinase. Ann Neurol 38(1): 58-67.

39. Guenthor AG, Arauz A (2011) Cerebral venous thrombosis: A diagnostic and treatment update. Neurologia 26(8): 488-498.

40. Stam J (2017) Thrombolysis or Anticoagulation for Cerebral Venous Thrombosis (TOACT). Clinical Trials Gov Identifier: NCT 01204333.

41. Rettinger G (2007) Risks and complications in rhinoplasty. GMS Curr Top Otorhinolaryngeol Head and Neck Surgery 6: Doc.8.

42. Keles MK, Aksakal IA, Park TH, Yagmur C, Kucuker I (2016) Unintentional Complications after Uneventful Rhinoplasty Operations: Case Reports and a Review of the Literature. Aesthetic Plast Surg 40(1): 54-61.

43. Longman (1831) Bright R Reports of Medical Cases ( $2^{\text {nd }}$ edn). London.

\section{Your next submission with Juniper Publishers will reach you the below assets}

- Quality Editorial service

- Swift Peer Review

- Reprints availability

- E-prints Service

- Manuscript Podcast for convenient understanding

- Global attainment for your research

- Manuscript accessibility in different formats

( Pdf, E-pub, Full Text, Audio)

- Unceasing customer service

Track the below URL for one-step submission https://juniperpublishers.com/online-submission.php 